\title{
A Experiência Vivida de Mulheres na Conjugalidade Contemporânea: Uma Análise com Iramuteq
}

\author{
Rafaelle Fernanda Costa Benevides ${ }^{1}$ \\ ${ }^{1}$ Universidade de Fortaleza, Ceará, Brasil.
}

\author{
Georges Daniel Janja Bloc Boris ${ }^{1}$ \\ ${ }^{1}$ Universidade de Fortaleza, Ceará, Brasil.
}

Resumo: Este estudo apresenta os resultados obtidos a partir de pesquisa de mestrado, realizada com o objetivo de compreender a experiência vivida de mulheres de classe média na conjugalidade contemporânea. Para a etapa de coleta de dados foi realizada uma entrevista semiestruturada, com uma pergunta disparadora. Com o objetivo de garantir maior robustez e fidedignidade à etapa de análise dos conteúdos obtidos por meio das entrevistas, foi utilizado o software livre Iramuteq no processamento dos dados, que gerou cinco diferentes classes, posteriormente denominadas e criteriosamente analisadas quantitativa e qualitativamente. Os resultados da pesquisa apontaram para as mudanças ocorridas na vida das mulheres após a maternidade e a forma como os cônjuges dividem as atividades domésticas e de cuidados com os filhos. Os resultados evidenciaram também os conflitos e ambivalências entre as exigências estabelecidas socialmente pelos papéis do gênero feminino e as experiências vividas por essas mulheres na conjugalidade contemporânea.

Palavras-chave: Mulheres, Conjugalidade contemporânea, Papéis de gênero, Iramuteq.

\section{Women's Lived Experience in Contemporary Conjugality: An Analysis with Iramuteq}

\begin{abstract}
This study reports the results a master's degree research that aimed to understand the lived experience of middle-class women in contemporary conjugality. Data were collected using, a semi-structured interview with a triggering question to guarantee greater robustness and reliability in the analysis, data were processed using Iramuteq free software, which generated five different classes that were later named and carefully analyzed quantitatively and qualitatively. The results indicate changes in the lives of women after motherhood, as well as the way spouses share household and child care activities. Moreover, they revealed the conflicts and ambivalences between socially established demands regarding feminine roles and these woman's lived experiences in contemporary conjugality.
\end{abstract}

Keywords: Women, Contemporary conjugality, Gender roles, Iramuteq. 


\title{
La Vivencia de Mujeres en la Conyugalidad Contemporánea: Un Análisis con Iramuteq
}

\begin{abstract}
Resumen: Este estudio presenta los resultados de la investigación de maestría cuyo objetivo fue comprender la vivencia de mujeres de clase media en la conyugalidad contemporánea. Para la etapa de recolección de datos, se realizó una entrevista semiestructurada con una pregunta disparadora. Con el objetivo de garantizar mayor solidez y fiabilidad da la etapa de análisis de los contenidos de las entrevistas, se utilizó el software libre Iramuteq en el procesamiento de los datos, en el cual emergieron cinco diferentes clases que fueron posteriormente denominadas y cuidadosamente analizadas cuantitativa y cualitativamente. Los resultados apuntan a los cambios ocurridos en la vida de las mujeres después de la maternidad y la forma cómo los cónyuges dividen los trabajos domésticos y de cuidado con los hijos. Además, evidencian los conflictos y ambivalencias entre las exigencias establecidas socialmente por los roles del género femenino y las vivencias de esas mujeres en la conyugalidad contemporánea.
\end{abstract}

Palabras clave: Mujeres, Conyugalidad contemporánea, Roles de género, Iramuteq.

\section{Introdução}

O feminismo é um movimento que tem como principal objetivo a equidade entre homens e mulheres, pois a maior parte das sociedades em que impera a concepção binária e dicotômica dos gêneros concede privilégios aos homens e coloca as mulheres em posições de desvantagem (Connell \& Pearse, 2015).

A dicotomia baseada no binômio homem/mulher tem sido apresentada invariavelmente em todas as sociedades que se tem conhecimento e é impossível não reconhecer que há uma assimetria nessa divisão. Esse dualismo e essa assimetria são baseados na verdade do corpo, sustentada por certa supremacia da força física masculina, que se estende a todos os níveis da vida por intermédio de uma ideologia que se apossa de tal dicotomia. Foi a partir dessa oposição entre homens e mulheres, baseada nas características físicas dos corpos, que as funções e papéis de cada gênero foram estabelecidas nas sociedades ocidentais (Badinter, 1986).

As concepções atuais desses papéis sociais são reflexo de uma repressão instaurada a partir de uma lógica burguesa vitoriana que tomou posse da sexualidade, enclausurando-a na finalidade de procriação e delegando à família e ao casal heterossexual os direitos sobre os discursos e práticas da sexualidade (Foucault, 1999). A mulher foi relegada a um lugar secundário na sociedade e, em muitas delas, a mulher foi considerada a personificação do mal, sendo alguns papéis biológicos, como a amamentação, tratados como execráveis (Beauvoir, 1949/2016).

Mesmo nas sociedades em que se observava alguma igualdade entre homens e mulheres na vida econômica e religiosa, a vida delas ainda parecia bem menos agradável que a dos homens. Significados de depreciação eram atribuídos aos corpos femininos e em algumas dessas sociedades os papéis de esposa e mãe eram desvalorizados, cabendo às mulheres a personificação de atividades carnais socialmente condenáveis (Badinter, 1986).

$\mathrm{O}$ tratamento dado às mulheres, bem como a maldade e lascívia atribuídas a elas, foram sistematicamente reforçados pelos discursos religiosos que tomaram como base o mito do Éden para a explicação do início da humanidade. Nos discursos religiosos mais antigos, a razão para que se tenha descrito a mulher dessa forma repousa na ideia de que existe uma natureza feminina de "sensualidade desenfreada, impossível de ser satisfeita por um só homem" (Badinter, 1986, p. 135). Esses discursos sociais, culturais e religiosos tomavam as mulheres e a sexualidade feminina como perigosas à ordem social e à constituição e manutenção da família.

No decorrer dos séculos, ocorreram transformações nas concepções sobre a natureza, o trabalho, o casamento, a família e a mulher, que passou a perder o simbolismo místico que a peculiarizava quando os 
homens a relacionavam à terra à medida que a natureza ia sendo domada pelos homens (Beauvoir, 1949/2016).

Historicamente, o casamento se tornou um dispositivo de poder do homem sobre a mulher, o ápice da organização social que deveria refletir uma hierarquia natural e universal, na qual a mulher ocuparia uma posição inferior. A partir desse momento, a igualdade entre homens e mulheres poderia ser considerada algo cada vez mais distante da realidade, passando a ser considerada, inclusive, uma heresia (Badinter, 1986). A mulher não possuía representatividade social e era constantemente negada como sujeito. A figura feminina era praticamente inexistente ou omitida nas representações da vida social, o que se revelou no trabalho iconográfico de Ariès (1981), demonstrando que até o século XV, a família era representada nas artes única e exclusivamente pela imagem do homem, o homem público que ocupava lugar central a sociedade e na família.

Foi nos séculos XVI e XVII que a representação da mulher e dos filhos nos retratos de família passou a demonstrar uma preocupação em situar a mulher e seu papel na sociedade. Elas passaram a ser representadas nas artes dessa época acompanhadas dos temas do casamento e do parto, ou seja, papéis relacionados ao cuidado (Ariès, 1981).

Havia grande preocupação com a definição dos papéis atribuídos às mulheres e os lugares que elas deveriam ocupar na sociedade, para garantir que se restringissem ao espaço doméstico e se submetessem à autoridade do patriarca, realizando tarefas de cuidado e educação dos filhos. Nesse sentido, foram criados discursos sobre a mulher em relação à família, que tinham como intuito legitimar a crença de que a ausência da mulher no lar destruiria a sociedade. Se a mulher não estivesse ocupando o lugar que foi dado a ela, seria considerada culpada pelo afrouxamento dos laços familiares e a debilitação da raça, "pois as crianças cresceriam mais soltas, sem a constante vigilância das mães" (Rago, 2009, p. 585).

A Revolução Francesa, ao final do século XVIII, que tinha ideais supostamente igualitários e libertários, elevou a família a um patamar mais alto e reforçou o papel materno que as mulheres deveriam desempenhar nesse núcleo. Souza (2003) defende que o pensamento do filósofo iluminista Rousseau influenciou fortemente tal papel da mulher, reforçando os preconceitos do Antigo Regime e os discursos criados na época, que robusteciam a crença de que as mulheres deveriam ocupar uma posição de sub- missão ao marido, legando à posteridade uma ideia de fragilidade, submissão e inferioridade do feminino.

Foi com os discursos filosófico e médico do século XVIII, muito baseados na ideia de natureza feminina, que se instaurou outra forma de dominação dos homens sobre as mulheres, não somente no que se referia às suas responsabilidades com o lar e com os filhos, mas também aos corpos. Com a justificativa de que, para o bem coletivo, era necessário administrar as taxas de natalidade e fecundidade, a conduta sexual das mulheres foi tomada como objeto de análise e, ao mesmo tempo, como algo passível de intervenção (Foucault, 1999). Como produto desses discursos, as mulheres passaram a ser vistas como a soma de atributos negativos e positivos, além de serem consideradas seres socialmente perigosos, que deveriam ser submetidos a um conjunto de medidas normatizadoras rígidas, assecuratórias de que cumpririam seu papel na sociedade e na família (Engel, 2009).

Na última década do século XIX o processo de modernização se intensificou no Brasil, atrelado à crescente urbanização e à industrialização (Matos \& Borelli, 2013).

Na transição para o século XX, as mulheres já eram autorizadas a trabalhar e, por exigência de um maior contingente de força trabalhadora, foram enviadas às fábricas onde desempenhavam atividades que foram progressivamente desvalorizadas. A elas destinavam-se os trabalhos monótonos, repetitivos e pouco qualificados em termos de hierarquia (Matos \& Borelli, 2013).

A industrialização absorveu muitas das atividades exercidas pelas mulheres em seus lares, como a fabricação de tecidos, pães e doces, o que acabou desvalorizando os serviços relacionados ao lar e à mulher. Além das obrigações que já tinham no lar e no cuidado com os filhos, as mulheres das classes mais baixas também se viram obrigadas a trabalhar fora de suas casas para complementar o orçamento familiar. Novos discursos emergiram a partir da modernidade e trataram de criar distinções entre as mulheres das classes mais baixas e das classes mais altas (Rago, 2009).

Foi na década de 1960, com a emergência da pílula anticoncepcional e da pílula abortiva, que as práticas reprodutivas foram radicalmente alteradas e foi possível fazer uma separação definitiva entre sexualidade e reprodução. Nas décadas posteriores, as mulheres puderam planejar ou até mesmo evitar uma gravidez. A despeito de todos esses avanços, o discurso religioso seguia repudiando os métodos 
contraceptivos e o aborto, culpabilizando as mulheres que realizavam essa prática. A Igreja Católica, com o passar do tempo, foi diminuindo sua resistência com relação aos métodos contraceptivos ainda considerados pela instituição como formas ilícitas de regulação dos nascimentos para concentrar esforços na condenação moral e política do aborto (Diniz, 2013).

No Brasil das décadas de 1960 e 1970, as mulheres participaram ativamente das mudanças sociais e políticas, tendo seus direitos humanos gravemente violados durante a ditadura (1964-1985), que se constituiu como um período de extrema misoginia (Teles, 2015) expressa na forma de repressão e tentativa de silenciamento das mulheres.

O estudo de Muraro (1983) também contribuiu fortemente para a compreensão da crescente participação das mulheres na história do Brasil. A partir dos estudos feministas sobre as condições econômicas das famílias, foi possível obter muitas informações sobre as condições de vida e a sexualidade da mulher brasileira, retratando um período de mudanças econômicas e, consequentemente, ideológicas no Brasil.

Os estudos de diversos pensadores sociais (Beauvoir, 1949/2016; Figueiredo, 2009; Matos \& Borelli, 2013; Miguel, 2017; Muraro, 1983; Rago, 2009; Raminelli, 2009; Souza, 2003; Teles, 2015; Toscano \& Goldenberg, 1992) apontam nitidamente para o fato de que, apesar de suas resistências, as mulheres foram destituídas de seu protagonismo na história e afastadas de atividades importantes à sociedade, atribuídas aos homens, que criaram para eles espaços de atuação nos quais foi possível legitimar seu poder.

Essa situação é constantemente criticada e as necessidades emergentes na atualidade têm convocado as pessoas a refletirem sobre os papéis de gênero. A crescente demanda de profissionais no mercado de trabalho, em todas as áreas, tem estreitado cada vez mais as distâncias entre os papéis femininos e masculinos na sociedade, o modelo patriarcal tem experimentado um crescente esfacelamento e o mito da virilidade já não encontra mais condições para ser amplamente sustentado, nem pelos homens nem pelas mulheres (Boris, 2011).

Essas mudanças ainda estão em curso e não ocorrem sem conflitos entre as dimensões pessoais, do trabalho e da família. Esses conflitos são ressaltados pelo estudo de Madalozzo e Blofield (2017), que enfa- tiza a participação dos pais na criação dos filhos em famílias de baixa renda de São Paulo. O estudo conclui que, mesmo com todas as mudanças, os homens que não residem com os filhos não contribuem sequer financeiramente, e as mulheres sofrem com a dupla jornada, suportando um peso ainda desproporcional para sustentar o lar e cuidar dos filhos.

A crescente participação feminina no mercado de trabalho e sua consequente ausência no lar impõe a necessidade de divisão das obrigações domésticas. Isso tem gerado uma espécie de barganha entre os sexos, que tende a favorecer o estabelecimento de relações mais igualitárias, mas que, ao mesmo tempo, mistura-se ao desejo das mulheres de não abrirem mão de um dos poucos espaços de poder do qual dispõem (Unbehaum, 2001).

Mesmo com todas as mudanças ocorridas até o momento, é preciso relacionar os fatores econômicos, históricos e culturais que as propiciaram, questionando os discursos ainda existentes sobre as mulheres para que o casamento e a família não se perpetuem como espaços de opressão (Benevides, 2018).

O estudo de Ramos (2015) corrobora essa ideia ao afirmar que os discursos naturalizantes que ainda existem na contemporaneidade foram criados por uma ordem econômica dominante que visava restringir as tendências críticas à realidade existente. É por essa razão que é preciso demonstrar como a organização familiar e a moral sexual já sofreram e devem continuar sofrendo modificações, sob pena de perpetuação das desigualdades entre homens e mulheres.

Apesar das transformações ocorridas na sociedade e nas configurações familiares contemporâneas, a constituição dos valores familiares e da sociedade como um todo continua centralizada nos discursos masculinos e na figura do homem como aquele que gerencia, administra, autoriza e manda. É ainda sobre a não legitimação, sobre a exploração e sobre a negação da mulher que se constituíram muitos valores atuais que regem as relações entre homens e mulheres na conjugalidade contemporânea (Benevides, 2018).

As novas formas de associação entre homens e mulheres, suscitadas pelas novas necessidades econômicas, as barganhas entre os sexos, as atuais exigências socioeconômicas têm sido foco de diversos estudos e constituem material que merece análise mais aprofundada sobre os papéis do homem e da mulher na conjugalidade e na família (Benevides, 2018). 


\section{Método}

Trata-se de uma pesquisa qualitativa de caráter descritivo, que teve como objetivo compreender a experiência vivida de mulheres na conjugalidade contemporânea. As participantes do estudo foram mulheres cearenses de classe média que residiam em Fortaleza, casadas, com filhos e que realizavam atividades profissionais remuneradas. Candidataram-se à pesquisa 12 mulheres, sendo uma participante de classe baixa, dez de classe média e uma de classe alta. Foram selecionadas para participação aquelas que pertenciam à classe média por representarem o maior número a se disponibilizar para a pesquisa. A classe média também representa a faixa mais numerosa de pessoas na sociedade brasileira, sendo este dado também considerado, de forma secundária, para a seleção.

Ao todo, foram dez participantes, com faixas etárias entre 26 e 48 anos, casadas havia pelo menos 1 ano e 7 meses e tinham de um a dois filhos com idades entre seis meses e 25 anos.

Tendo em vista os critérios de exclusão das participantes, não interessaram a esta pesquisa as mulheres solteiras ou divorciadas e sem filhos, ou cujos filhos não convivessem com o casal, considerando o fato de que ter um cônjuge e um ou mais filhos alterava as condições sociais e econômicas da mulher. Não foram aceitos cônjuges que vivessem em domicílios diferentes por quaisquer razões. Também foi um critério de exclusão a nacionalidade estrangeira de qualquer um dos cônjuges, devido aos fatores culturais que pudessem vir a interferir na dinâmica dos casais.

A pesquisa utilizou a entrevista semiestruturada como instrumento de coleta de dados, partindo da pergunta disparadora "como é ser mulher?", que deixava em aberto as possibilidades de fala das participantes, sem direcioná-las explicitamente ao objeto do estudo - a experiência vivida de mulheres na conjugalidade contemporânea.

As falas das participantes foram formatadas para análise com o software livre Iramuteq que, segundo Camargo e Justo (2013), viabiliza diferentes tipos de análise de dados textuais, desde as mais simples, como a lexicografia básica (cálculo de frequência de palavras), até análises multivariadas como a classificação hierárquica descendente (CHD) utilizada neste estudo.

A análise CHD é uma das principais e mais importantes oferecidas pelo Iramuteq, pois é a partir dela que os segmentos de textos e seus vocábulos podem ser correlacionados, formando um esquema hierárquico de classes de vocabulário. A partir desta análise, o pesquisador pode inferir o conteúdo do corpus, compreender os grupos de discursos presentes nesse corpus e dar nome às classes.

Conforme Kami et al. (2016), é importante ressaltar que o Iramuteq não é um método de análise de dados, mas uma ferramenta de apoio ao pesquisador no processamento dos dados textuais. A análise e interpretação dos dados é de inteira responsabilidade do pesquisador. Nesse sentido, o software foi utilizado neste estudo para garantir maior robustez e fidedignidade à análise dos resultados, evitando também possíveis tendências ao subjetivismo na etapa de análise.

Como instrumento para o processamento de dados textuais obtidos por meio de entrevistas, o Iramuteq apresenta rigor estatístico e permite ao pesquisador utilizar diferentes recursos técnicos de análise lexical. Como vantagens, o software apresenta interface simples e facilmente compreensível e seu acesso é gratuito, do tipo open source. Por estas razões acredita-se que o software possa trazer muitas contribuições ao campo de estudo das ciências humanas e sociais, em diversos países do mundo, e em especial nos de língua portuguesa (Camargo \& Justo, 2013).

No processamento dos dados textuais, o Iramuteq gerou cinco categorizações do conteúdo total. A partir delas, as cinco classes foram denominadas e criteriosamente analisadas, considerando as falas parciais geradas pelo software e o conteúdo total do corpus em questão.

Os nomes das participantes foram substituídos por pseudônimos que não revelam nenhum tipo de ligação com elas. Toda a pesquisa foi realizada sob a aprovação do Comitê de Ética, que tem como objetivo defender os interesses das participantes da pesquisa em sua integridade e dignidade, além de avaliar e monitorar o andamento da pesquisa, de modo que os princípios éticos de proteção aos direitos humanos, da dignidade, da autonomia, da não maleficência, da confidencialidade e da privacidade sejam plenamente respeitados.

\section{Resultados}

Os resultados foram obtidos a partir da análise CHD, também denominada como Método de Reinert. Esta análise visa obter classes de Unidades de Contexto Elementares (UCE) que, ao mesmo tempo, apresentam vocabulário semelhante entre si 
e vocabulário diferente das UCE das outras classes (Camargo \& Justo, 2013).

Após o input dos dados, o software apontou um corpus total constituído por 10 textos, separados por um total de 1.085 segmentos de textos (ST), dos quais foram aproveitados $912 \mathrm{ST}(84,06 \%)$. Emergiram 44.007 ocorrências (palavras, formas ou vocábulos), sendo 3.457 palavras distintas (número de formas) e 1.718 com uma única ocorrência (número de hapax).

O conteúdo analisado foi categorizado em cinco classes, distribuídas da seguinte forma: classe $1 \mathrm{com}$ 246 ST (27\%); classe 2 com 263 ST (28,8\%); classe 3 com 119 ST (13,1\%); classe 4 com 128 ST (14\%); e classe 5 com 156 ST (17,1\%), de um total de 912 ST (Figura 1).

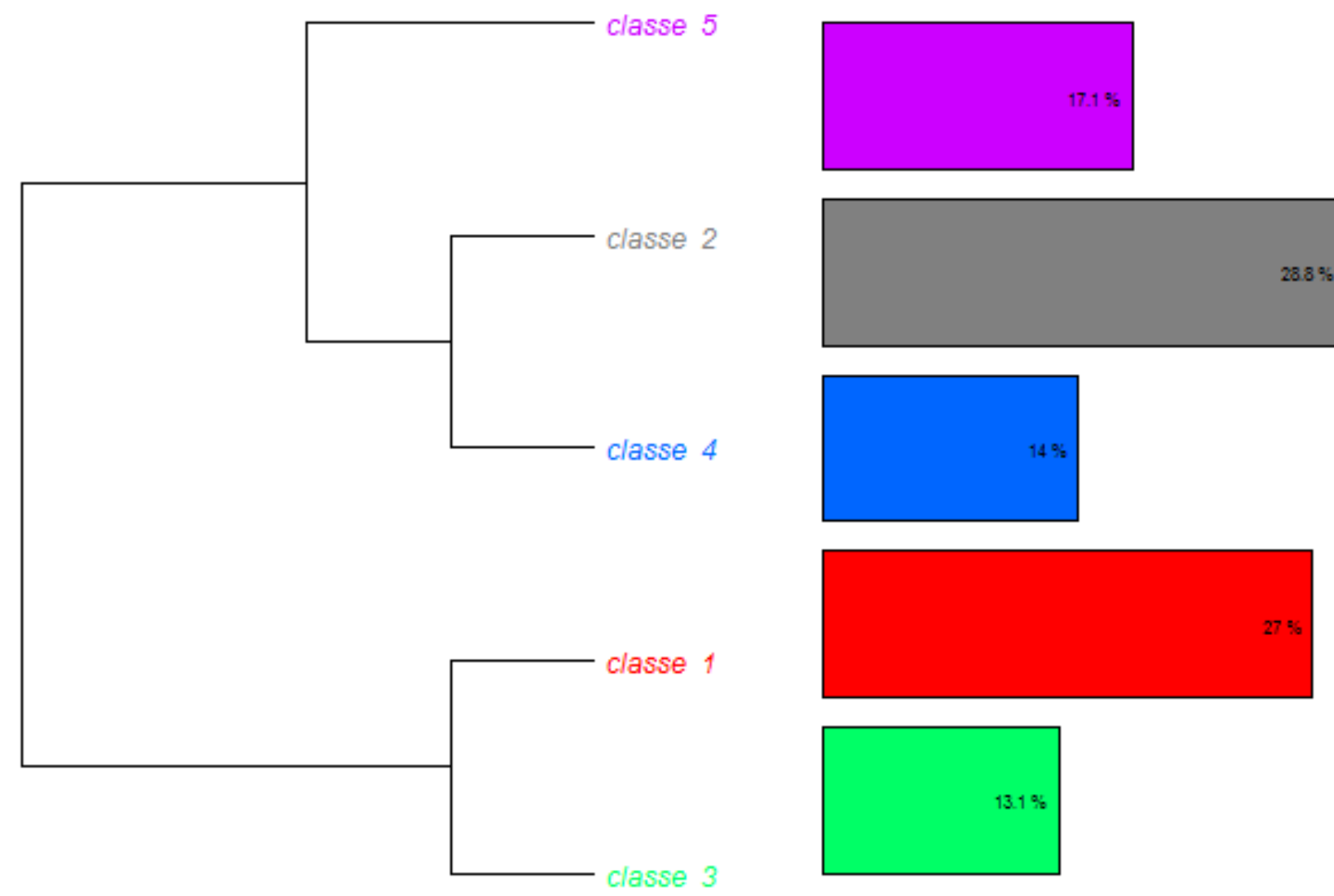

Figura 1

Gráfico gerado pelo software Iramuteq, constituído por 5 classes de Unidades de Contexto Elementares (UCE), a partir da análise CHD, ou Método de Reinert.

Realizando uma análise mais aprofundada, foram verificadas as palavras contidas em cada classe para que fosse possível denominá-las. Para isso, utilizou-se a segunda forma de apresentação dos dados na análise CHD (Figura 2), que gera dendrogramas, representações esquemáticas ou diagramas semelhantes à estrutura de uma árvore.

Para melhor compreensão das Figuras 1 e 2, é importante informar que as classificações apresentadas são resultado de uma seleção e agrupamento dos termos por lematização, que é uma seleção realizada automaticamente pelo Iramuteq, evitando assim qualquer tipo de tendenciosidade na seleção dos conteúdos. Para o entendimento da Figura 2, é importante salientar também que alguns caracteres como as aspas (") presentes nas falas das participantes da pesquisa foram substituídos por seus termos correspondentes para que a análise do conteúdo não sofresse alterações de sentido, diferenciando assim o que era uma citação de outrem dentro do discurso das participantes. Foram mantidas acentuações como exclamações e interrogações para que fosse possível uma interpretação fiel dos dados, assim como termos considerados pouco relevantes para o sentido das evocações, porém que garantiam maior fidedignidade aos conteúdos trazidos pelas falas das participantes. 


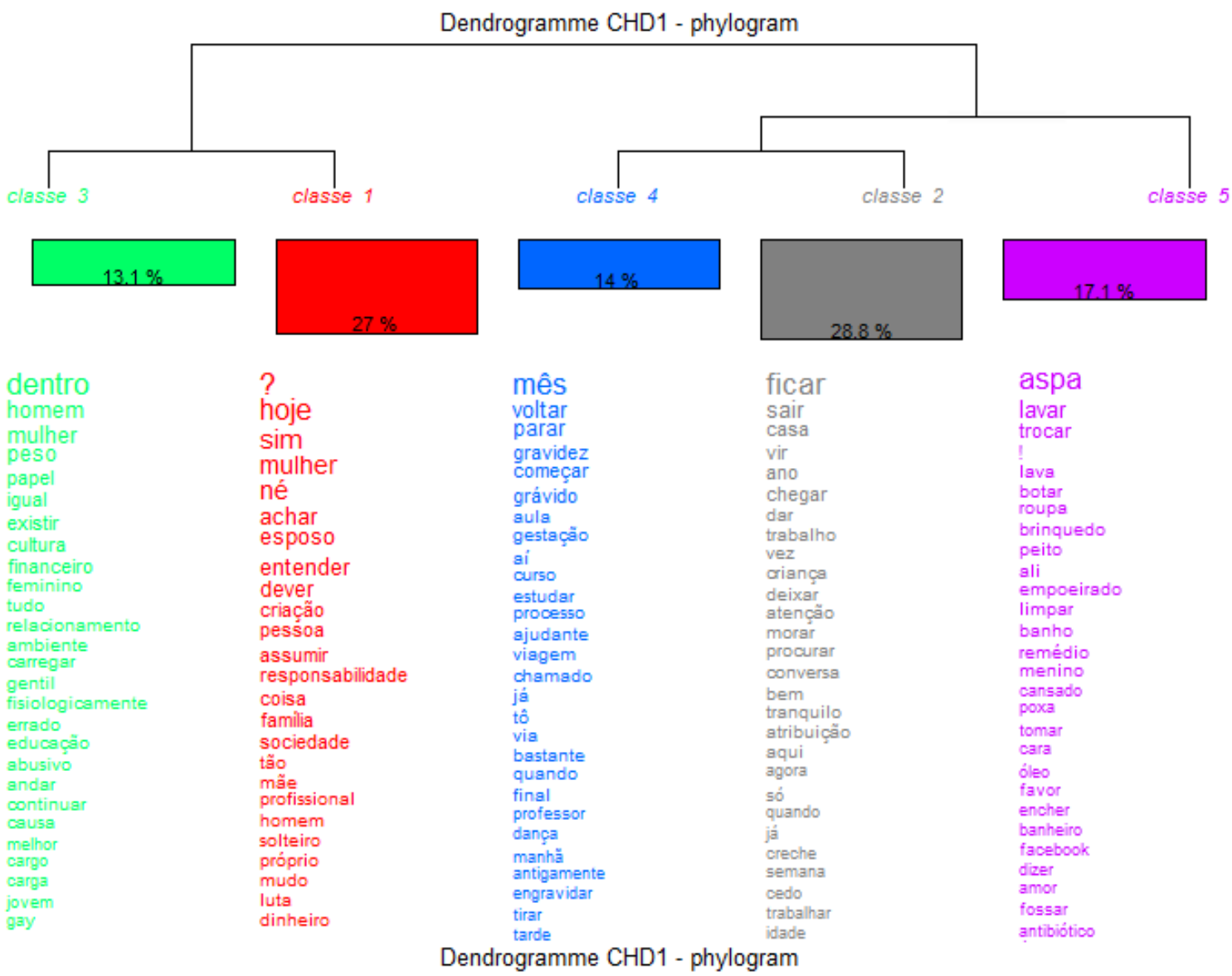

Figura 2

Dendrograma CHD1.

$\mathrm{Na}$ análise individual de cada uma das cinco classes, foi possível verificar o contexto em que foram utilizadas algumas palavras através da concordância dos segmentos. Verificamos que a classe 1 trata de aspectos referentes à situação de vida atual, como mulheres casadas, com filhos e que trabalham dentro e fora do lar. Nessa classe, foram compiladas as evocações das participantes que também demonstraram mudanças com relação ao seu passado, antes do casamento, por exemplo.

A classe 1 também faz referência à forma como as mulheres veem suas ancestrais, a forma como consideram que são vistas pela sociedade atual e como consideram que a situação das mulheres contemporâneas mudou com relação ao que era no passado. Desta forma, a classe 1 foi denominada "Mudanças na vida das mulheres contemporâneas”.

Essa classe compreende $27 \%$ (246 ST) do corpus total analisado e é constituída por palavras e radicais em um intervalo entre $\mathrm{x}^{2}=4,38$ (mudar) e $\mathrm{x}^{2}=43,15$ (hoje). Essa classe é composta pelas palavras "hoje" $\left(x^{2}>43,15\right)$ e "mudar" $\left(x^{2}>4,38\right)$, evidenciadas principalmente nas falas da participante Mayara, 31 anos, dois filhos, que diz: "meu pai não podia ir para a cozinha, minha avó achava isso um absurdo. Hoje, quem cozinha aqui é o T (marido da participante). Hoje em dia as coisas estão mudando". O recorte da fala de Mayara revela comparação entre o que vê como uma mudança na vida das mulheres o que via na vida de sua avó.

A participante Janaína, 35 anos, dois filhos, trouxe um relato sobre um período mais atual. Ela comparou sua vida quando era mãe solteira e após o casamento: "Até de convidar meu filho para as festas, aniversário de colegas. Isso mudou dentro de dois anos só porque eu tenho um companheiro. Então a mulher ainda precisa de um homem para legitimar a existência dela, entendeu?".

As falas da classe 1 demonstram também como as participantes consideram as transformações nos 
atuais papéis de gênero dentro da conjugalidade, porém essas evocações emergem mais fortemente na classe 3.

A classe 2 trata do nascimento dos filhos dos casais e de como a rotina é organizada, de forma que o ir e vir dos casais sofre alterações, desde os horários de saída para o trabalho até o horário de lazer e a vida social de ambos. A classe 2 foi então denominada de "Rotina familiar e profissional".

Essa classe compreende $28,8 \%$ (263 ST) do corpus total analisado e é constituída por palavras e radicais em um intervalo entre $\mathrm{x}^{2}=4,17$ (chegada) $\mathrm{e}^{2}=46,42$ (sair). A classe 2 também é composta por palavras como "trabalho" ( $\left.x^{2}>20,55\right)$, "criança" $\left(x^{2}>19,02\right)$, "horário" ( $\left.x^{2}>10,86\right)$ e "organizar" $\left(x^{2}>6,24\right)$. Essas palavras aparecem nas seguintes falas da participante Laura, 35 anos, mãe de uma filha: "eu acho que hoje em dia eu consigo me organizar melhor. Ainda tem dias que eu estou pra ficar louca, né?". Mayara também apresenta os termos em suas evocações quando diz: "eu tenho que estar lá, tenho que organizar, tenho que dizer o que é para fazer".

Essa classe também apresenta dados sobre a participação paterna na rotina dos filhos, na organização do material escolar e na administração de medicamentos para as crianças. As falas das participantes revelam que muitas das mães estão à frente dessas atividades, evidenciando menor participação dos pais em alguns aspectos da rotina dos filhos. Isso fica destacado na fala da participante Diana, 35 anos, mãe de um filho, quando diz: "ele (o cônjuge) acha bom demais, ele é louco pelo filho dele, mas ele não pensa no meu trabalho. Ele vê, mas não é na pele dele que ele sente".

Ainda com relação à palavra "trabalho" $\left(x^{2}>20,55\right)$, ela também representa a preocupação que as mulheres têm em manter as atividades profissionais e remuneradas que exercem, incluindo a reinserção no mercado após o nascimento dos filhos. Esse dado é apontado na seguinte fala da participante Mariana, 28 anos, mãe de um filho: "quando a gente é muito jovem, pode engravidar a qualquer momento $e$, aí, pode não ser muito bom para o mercado de trabalho, porque você não pode engravidar".

A rotina profissional e a preocupação com as obrigações laborais também influenciaram algumas participantes durante a amamentação dos filhos. A fala da participante Cláudia, 48 anos, mãe de dois filhos, elucida essa afirmação quando fala de outras mulheres de sua família: "não era costume as pessoas amamentarem. Vinte e cinco anos atrás não era. Ah, porque não tinha leite, desistia. E também assim, a maioria das minhas primas tinha que voltar ao trabalho, não tinha muito com quem deixar".

A classe 3 contempla a compreensão das entrevistadas sobre os papéis masculinos e femininos na sociedade e na família. Nessa classe, as mulheres discorreram sobre as igualdades e diferenças entre homens e mulheres e como entendiam as obrigações de cada cônjuge na criação dos filhos. Essa classe foi denominada "Papéis de gênero".

A classe 3 compreende 13,1\% (119 ST) do corpus total analisado e é composta por palavras e radicais no intervalo entre $x^{2}=4,07$ (diferente) e $x^{2}=77,34$ (homem). Também compõem essa classe as palavras "mulher" ( $\left.x^{2}>70,37 \%\right)$, "papel" $\left(x^{2}>48,64\right)$ e "cultura" ( $\left.x^{2}>47,01\right)$. A compreensão dos papéis culturalmente atribuídos a homens e mulheres nas atividades domésticas e no exercício da parentalidade fica evidenciada na seguinte fala da participante Mariana: "o meu marido é um, ele acha que mulher tem que ir ali, tem que cozinhar e tal. Beleza, ele cozinha quando ele quer, ele gosta de cozinhar, curte, mas, para ele, isso é um papel feminino".

No caso de casais nos quais a mulher é quem trabalha fora e o marido é quem fica em casa com os filhos, os papéis são considerados como estando invertidos. Isso é elucidado pela seguinte afirmação de Ana Paula, 44 anos, mãe de dois filhos: "então ele fica mais como se ele estivesse fazendo o meu papel e eu o dele, mas, de certa forma, eu tenho que estar no controle de tudo".

As entrevistadas, de forma geral, revelaram a crença de que há um papel baseado nas qualidades atribuídas à mulher e ao homem como sendo atributos femininos ou masculinos, e isso rege a dinâmica de obrigações de cada um na vida familiar. Essa afirmação é exemplificada por uma fala da participante Diana, ao dizer que "a mulher ainda tem aquela crença de que a mulher tem que cuidar da casa e da família. Realmente, éo papel dela porque ela é mais delicada e ela entende um pouco mais".

Ao mesmo tempo, as entrevistadas revelam conflito em relação ao papel atribuído ao homem e à mulher na parentalidade. $\mathrm{O}$ discurso de Mariana demonstra isso quando questiona:

por que ela é uma péssima mãe e ele não é um péssimo pai? Porque que a gente tem que ter esse papel, essa responsabilidade de a educação do filho ser 
nossa?". Ela também afirma que essa responsabilidade deve ser dividida entre os genitores quando questiona: "E o marido? Onde estava na história? E o pai da criança, que também está participando daquilo e é tão corresponsável quanto você?

Janaína, 35 anos, mãe de dois filhos, também traz a seguinte afirmativa: "espera-se sempre de uma mãe que ela seja... que ela tenha um papel meio passivo. Eu acho que a maternidade também é ativismo, sabe? Eu luto por uma maternagem, na verdade, ativa".

Janaína defende que o papel da maternidade é o de criar cidadãos conscientes e revela agir dessa maneira por julgar que ter maior responsabilidade é uma dívida social as outras mulheres por ser mãe de dois meninos.

A classe 4 é representada pelos conteúdos referentes às mudanças no corpo e na vida das mulheres, durante e após cada gestação, e às experiências vividas pelas entrevistadas no período de amamentação e de crescimento dos filhos. Essa classe também apresenta dados sobre a rotina das entrevistadas antes, durante e depois da gestação, além da preocupação com a estética, o peso e a autoestima, sendo denominada "Mudanças após a maternidade".

Essa classe compreende 14\% (128 ST) do corpus total analisado. É constituída por palavras e radicais no intervalo entre $\mathrm{x}^{2}=4$ (perder) e $\mathrm{x}^{2}=159,32$ (mês). Também compõem essa classe as palavras "amamentação" ( $\left.x^{2}>6,91\right)$; "corpo" ( $\left.x^{2}>7,7\right)$ e "gravidez" $\left(x^{2}>61,93\right)$.

A fala de Diana, na classe 4, demonstra como ela vivenciou a gestação: "assim, o corpo muda, esteticamente". Conteúdo similar é trazido na evocação de Janaína quando diz: "eu me lembro que, antes, eu chorava demais na minha primeira gravidez, depois que eu tive o $G$ (primeiro filho), porque minha barriga estava muito diferente, eu chorava tanto!".

Cláudia traz um dado significativo de sua experiência com o próprio corpo quando diz: "foi uma gravidez de risco, toda hora eu tinha ameaça de tê-lo antes do tempo, ai deitava", revelando que uma de suas gestações foi bastante delicada e a limitava na realização de atividades rotineiras.

A fala de Lurdes, 27 anos, mãe de dois filhos, também é contemplada por esta classe, quando ela relata: "tem a fase que entra bico, mamadeira, chupeta. São coisas do tipo que atrapalham a amamentação, atrapalha muita coisa no processo de relação filho-mãe".
A classe 5 trata das atividades domésticas das entrevistadas e da forma como essas responsabilidades são divididas entre os cônjuges e filhos na dinâmica familiar. De maneira geral, essa classe apresenta dados sobre a divisão das obrigações domésticas, sobre a forma como as entrevistadas realizam essas atividades e como executam, delegam ou compartilham as obrigações do lar com filhos e cônjuges. Foi denominada "Divisão das atividades domésticas".

Tal classe corresponde a $17,1 \%$ (156 ST) do corpus total analisado. É constituída por palavras e radicais em um intervalo entre $\mathrm{x}^{2}=4,61$ (compartilhar) e $x^{2}=91,11$ (lavar). Outras palavras que também compõem essa classe são "obrigação" $\left(\mathrm{x}^{2}>4,79\right)$; "cansada" ( $x>29,37)$ e "limpar" $\left(x^{2}>34,19\right)$.

As falas das entrevistadas demonstram como é a divisão das atividades de cuidados com o lar. Isso é evidenciado na evocação da participante Janaína que afirma que "ele (o marido) gosta mais. Ele gosta mais de cuidar da casa, de lavar, de passar. Eu não, eu sou mais prática. Assim, eu arrumo quando precisa, ele não, ele gosta de cuidar mesmo da casa".

O tema é abordado por Isadora, 33 anos, mãe de um filho: "eles (o cônjuge e o filho) têm esse cuidado comigo... Só isso, porque na hora de lavar pano, lavar chão ou essas coisas, eles não têm não".

A fala de Adriana, 26 anos, mãe de um filho, também traz dados sobre a forma como é vivenciada a divisão das atividades domésticas quando diz: "então, assim, em casa, basicamente eu faço tudo, entendeu? Lavar louça, lavar roupa, cuidar da minha filha... Ele é, basicamente, o papel financeiro".

Ana Paula revela sentir cobrança social sobre a realização das tarefas domésticas, ao mesmo tempo em que precisa apresentar uma boa aparência. Ela afirma que "você não pode transparecer que está cansada, que não teve tempo de ir ao salão".

A classe 5 trouxe à tona as evocações das participantes sobre a forma como vivenciam, junto aos cônjuges, a divisão do trabalho no lar, porém também evidenciou o modo como os cônjuges se posicionam diante das responsabilidades após o nascimento dos filhos, o que foi analisado sob a ótica da divisão do trabalho doméstico.

\section{Análise e discussão}

Os dados apontaram para a experiência vivida de mulheres da classe média na conjugalidade contemporânea, revelando que ainda há grandes assi- 
metrias de poder nas relações conjugais na contemporaneidade, sustentadas pelas antigas concepções dos papéis de gênero. Essas concepções ainda estão fortemente embasadas no discurso de natureza feminina, como citado por Badinter (1986), além de serem reforçadas pelo discurso religioso que impõe maiores responsabilidades às mulheres nos papéis de esposas e mães.

A maternidade aparece como a experiência que mais tende a modificar a rotina das participantes. Algumas das dimensões mais básicas da vida são transformadas após a chegada dos filhos, o que também inclui uma restrição da autonomia de ir e vir, redução do tempo para o lazer e cuidados pessoais, além da diminuição da remuneração, no caso das mulheres que trabalham de forma autônoma.

A chegada dos filhos também tende a alterar a dinâmica desses casais, principalmente relacionada à divisão das atividades domésticas. É nesse ponto que reside a maior assimetria nessas relações conjugais, um fenômeno já apontado por Beauvoir (1949/2016). As mulheres têm suas vidas, seus corpos e seu tempo profundamente alterados com as responsabilidades advindas do papel materno, que tende a aumentar a sobrecarga dessas mulheres com as atividades domésticas. Em contraposição, os cônjuges não se veem mais obrigados a cumprir com os afazeres domésticos após a chegada dos filhos, tampouco são restringidos em suas liberdades de ir e vir.

As falas analisadas a partir do corpus total revelou, segundos as participantes, que muitos dos cônjuges continuam realizando as mesmas atividades de antes da chegada dos filhos e que, em contrapartida, algumas mulheres foram impedidas, pelos próprios cônjuges, de manter atividades sociais, como saídas noturnas com as amigas.

O que a pesquisa aponta é a importância do questionamento sobre o papel feminino na conjugalidade contemporânea, que ainda tende a reproduzir os papéis opressores de outrora. A conjugalidade, para as participantes do estudo, não aparece como condição para a transformação de suas vidas, de seus corpos e de seu tempo, mas sim o exercício da maternidade. É na experiência vivida como mães que as mulheres revelam maior adequação aos papéis social e culturalmente estabelecidos em tempos anteriores e que estabelecem o lugar de opressão que as mulheres têm ocupado no decorrer da história.
Em algumas evocações, as participantes revelam certa indignação e repulsa ao papel a elas atribuído pela sociedade e exigidos pelos cônjuges, porém, apenas uma das participantes denota, de fato, práxis contestadoras dos modelos vigentes de comportamento, que relegam um lugar subalterno às mulheres. As demais participantes do estudo demonstraram conhecimento superficial e estereotipado do feminismo, levando em consideração que alguns dos questionamentos levantados pelo movimento chegam a ser considerados por elas como relevantes socialmente, porém não pertencentes às realidades vividas por elas, senão de forma distante e até acessória. É na aceitação e conformação evidenciadas nas falas das participantes que fica nítida a abstenção consciente e o desinteresse dessas mulheres pelas questões sociais e culturais que atravessam suas existências.

É no exercício do papel materno que as participantes denotam maior conformidade às regras de comportamento socialmente impostas a elas, apesar do conflito entre os interesses pessoais e familiares, como assinalado pelo estudo de Rago (2009). Poucas entrevistadas chegam a questionar essas regras, ainda assim, a reclamação e a indignação presentes em suas falas não denotam nenhum tipo de ação concreta para a transformação dessa realidade.

Talvez seja possível, através do questionamento sobre o exercício dos papéis materno e paterno, uma diminuição das assimetrias e desigualdades de poder entre homens e mulheres na relação conjugal. Este estudo, longe de representar a totalidade da experiência vivida por mulheres nas relações conjugais na contemporaneidade, apresenta evidências concretas de que poucas coisas realmente mudaram no papel social da mulher, senão pelo aumento das atribuições femininas no lar, no trabalho e na família, possivelmente consequentes das transformações econômicas e das novas necessidades sociais.

Este estudo assume sua limitação metodológica e epistemológica, deixando em aberto a possibilidade de novas pesquisas que busquem compreender a realidade vivida pelas mulheres nas atuais relações conjugais, além de propiciar problemas-chave para futuras discussões sobre os papéis exercidos pela mulher contemporânea na sociedade, no trabalho, no casamento, nos cuidados maternos e na família. 


\section{Referências}

Ariès, P. (1981). História social da criança e da família. Guanabara.

Badinter, E. (1986). Umé o outro. Nova Fronteira.

Beauvoir, S. (1949/2016). O segundo sexo: Fatos e mitos (3a ed., vol. 1, S. Milliet, Trad.) Nova Fronteira. (Trabalho original publicado em 1949)

Benevides, R. F. C. (2018). Tornar-se mulher: A experiência vivida na conjugalidade contemporânea sob uma perspectiva fenomenológico-existencial. [Tese de mestrado, Universidade de Fortaleza]. BDTD. https://uol.unifor.br/ oul/conteudosite/?cdConteudo $=8720540$

Boris, G. D. J. B. (2011). Falas de Homens: A construção da subjetividade masculina. Annablume.

Camargo, B. V., \& Justo, A. M. (2013). Iramuteq: Um software gratuito para análise de dados textuais. Temas em psicologia, 21(2), 513-518. http://doi.org/10.9788/TP2013.2-16

Connell, R., \& Pearse, R. (2015). Gênero: Uma perspectiva global. NVersos.

Diniz, D. (2013). Três gerações de mulheres. In C. B. Pinsky, \& J. M. Pedro (Orgs.), Nova história das mulheres no Brasil (pp. 313-332). Contexto.

Engel, M. (2009). Psiquiatria e feminilidade. In M. Del Priori, \& C. Bassanezi (Orgs.), História das mulheres no Brasil (pp. 322-361). Contexto.

Figueiredo, L. (2009). Mulheres nas Minas Gerais. In M. Del Priori, \& C. Bassanezi (Orgs.), História das mulheres no Brasil (pp. 141-188). Contexto.

Foucault, M. (1999). História da sexualidade I. A vontade de saber (M. T. C. Albuquerque, \& J. A. G. Albuquerque, Trads.). Graal.

Kami, M. T. M., Larocca, L. M., Chaves, M. M. N., Lowen, I. M. V., Souza, V. M. P. D., \& Goto, D. Y. N. (2016). Trabalho no consultório na rua: Uso do software Iramuteq no apoio à pesquisa qualitativa. Escola Anna Nery, 20(3), 1-5. https:// doi.org/10.5935/1414-8145.20160069

Madalozzo, R., \& Blofield, M. (2017). Como famílias de baixa renda em São Paulo conciliam trabalho e família. Revista Estudos Feministas, 25(1), 215-240. https:// doi.org/10.1590/1806-9584.2017v25n1p215

Matos, M. I., \& Borelli, A. (2013). Espaço feminino no mercado produtivo. In C. B. Pinsky, \& J. M. Pedro (Orgs.), Nova história das mulheres no Brasil (pp. 126-147). Contexto.

Miguel, L. F. (2017). Voltando à discussão sobre capitalismo e patriarcado. Revista Estudos Feministas, 25(3), 12191237. https:// doi.org/10.1590/1806-9584.2017v25n3p1219

Muraro, R. M. (1983). Sexualidade da mulher brasileira: Corpo e classe social no Brasil. Vozes.

Rago, M. (2009). Trabalho feminino e sexualidade. In M. Del Priori, \& C. Bassanezi (Orgs.), História das mulheres no Brasil (pp. 578-606). Contexto.

Raminelli, R. E. T. (2009). Eva Tupinambá. In M. Del Priori, \& C. Bassanezi (Orgs.), História das mulheres no Brasil (pp. 11-44). Contexto.

Ramos, R. L. S. (2015). Função da mulher na família: Uma crítica marxista. Problemata: Revista Internacional de Filosofia, 6(3), 129-145. https://doi.org/10.7443/problemata.v6i3.25383

Souza, I. (2003). A mulher e a revolução francesa: Participação e frustração. Revista da FARN, 2(2), 111-124.

Teles, M. A. A. (2015). Violações dos direitos humanos das mulheres na ditadura. Revista Estudos Feministas, 23(3), 1001-1022. https://doi.org/10.1590/0104-026X2015v23n3p1001

Toscano, M., \& Goldenberg, M. (1992). A revolução das mulheres: Um balanço do feminismo no Brasil. Revan.

Unbehaum, S. G. (2001). A desigualdade de gênero nas relações parentais: O exemplo da custódia dos filhos. In M. Arilha, S. G. Unbehaum, \& B. Medrado (Orgs.), Homens e masculinidades: Outras palavras (pp. 163-184). Editora 34. 


\section{Rafaelle Fernanda Costa Benevides}

Psicóloga e mestre em Psicologia pela Universidade de Fortaleza (Unifor), Fortaleza - CE. Brasil.

E-mail: rafaellebenevides@edu.unifor.br

(D) https://orcid.org/0000-0003-2690-5783

Georges Daniel Janja Bloc Boris

Psicólogo, mestre em Educação e doutor em Sociologia pela Universidade Federal do Ceará (UFC). Docente da graduação e pós-graduação em Psicologia na Unifor, Fortaleza - CE. Brasil.

E-mail: geoboris@unifor.br

(D) https://orcid.org/0000-0003-0726-1767

Endereço para envio de correspondência:

Universidade de Fortaleza (Unifor). Av. Washington Soares, 1321, Edson Queiroz. CEP: 60811-905. Fortaleza-CE. Brasil.

Recebido 07/06/2018

Aceito 25/04/2019

Received 06/07/2018

Approved 04/25/2019

Recibido $07 / 06 / 2018$

Aceptado 25/04/2019

Como citar: Benevides, R. F. C., \& Boris, G. D. J. B. (2021). A experiência vivida de mulheres na conjugalidade contemporânea: Uma análise com Iramuteq. Psicologia: Ciência e Profissão, 41 (n.spe 3), 1-12. http://doi.org/10.1590/1982-3703003202611

How to cite: Benevides, R. F. C., \& Boris, G. D. J. B. (2021). Women’s lived experience in contemporary conjugality: An analysis with Iramuteq. Psicologia: Ciência e Profissão, 41 (n.spe 3), 1-12. http://doi.org/10.1590/19823703003202611

Cómo citar: Benevides, R. F. C., \& Boris, G. D. J. B. (2021). La vivencia de mujeres en la conyugalidad contemporánea: Un análisis con Iramuteq. Psicologia: Ciência e Profissão, 41 (n.spe 3), 1-12. http://doi.org/10.1590/19823703003202611 